[Technical Paper]

\title{
Large-Area Chip Attachment by Sintering Nanosilver Paste: Process Improvement by Nondestructive Characterization
}

\author{
Kewei Xiao*,**, Jesus Calata*,**, Khai Ngo*,***, Dimeji Ibitayo****, and Guo-Quan Lu*,**,*** \\ *Center for Power Electronics Systems, Virginia Polytechnic Institute and State University, Blacksburg, VA 24061, USA \\ **Department of Materials Science and Engineering, Virginia Polytechnic Institute and State University, Blacksburg, VA 24061, USA \\ ***The Bradley Department of Electrical and Computer Engineering, Virginia Polytechnic Institute and State University, Blacksburg, VA 24061, USA \\ ****Army Research Laboratory, 2800 Powder Mill Rd, Adelphi, MD 20783, USA
}

(Received August 15, 2011; accepted November 28, 2011)

\begin{abstract}
Low-temperature joining with sintered silver is being developed as a lead-free, non-solder, die-attach solution for packaging power devices and modules. While its feasibility has been demonstrated, one major drawback of sintered silver joint is the high applied pressure during sintering to produce the desired bond strength. A high percentage of voids could also remain in the sintered joints. Applying the technique to large-area attachments also means a correspondingly higher applied pressure, and damage to the devices and substrates is possible. This study focused on the use of nanosilver paste as an attachment material that can be sintered at relatively low temperatures and pressures. Because of the difficulty of obtaining the die-shear strength of very large attachments, two non-destructive methods, micro X-ray computed tomography (CT) and curvature measurement using a laser-scanning technique, were used to characterize the bonded structures. Effects of different drying and sintering conditions on the bonding qualities were discussed.
\end{abstract}

Keywords: Low-temperature Joining, Nanosilver Paste, Nondestructive Characterization, X-ray Imaging, Curvature Measurement

\section{Introduction}

Die-attach by silver sintering has been investigated as an alternative to solder or epoxy in the fabrication of electronic packages and modules. Because the resulting sintered silver has a high melting point, it can be used in packages at operating temperatures in excess of $250^{\circ} \mathrm{C}$, which is significantly higher than the working temperatures of most traditional solder-based or epoxy-based materials.[1] Other advantages include good mechanical, thermal and electrical properties, [2] and good ductility. [3-6] Being free of lead and other heavy metals also means that the sintered silver die-attach is RoHS compliant.

One major issue with a sintered silver joint, as currently implemented, is that it requires a high applied pressure during sintering. [7] A high percentage of voids could also remain in the sintered joint.[8, 9] Large-area bonding also means an increasingly high applied pressure, and the components may be susceptible to damage at such a high pressure.
To show the advantages of reduced particle size, we used a nanoscale silver paste $\left(\right.$ nanoTach $\left.^{\circledR}\right)$ from NBE Technologies, LLC (Blacksburg, Virginia) as the attachment material for high temperature packaging. Unlike pastes containing micrometer-sized particles, the nanosilver paste can be sintered at relatively low temperatures and pressures. Large-area silicon chips with silver metallization were used as devices in this study. Obtaining the bond strength of large-area attachments proved difficult because the silicon usually cracked. As a result, we decided to employ non-destructive methods to indirectly infer the strength of the attachments produced with the sintered paste. These methods are micro X-ray computed tomography (CT) and curvature measurement by laser. The micro X-ray CT is capable of imaging the bulk volume of the sintered layer, clearly showing any voids and cracks that may be present, while scanning the chip surface with a laser enables detection of the curvature induced by the coefficient of thermal expansion (CTE) mismatch between 


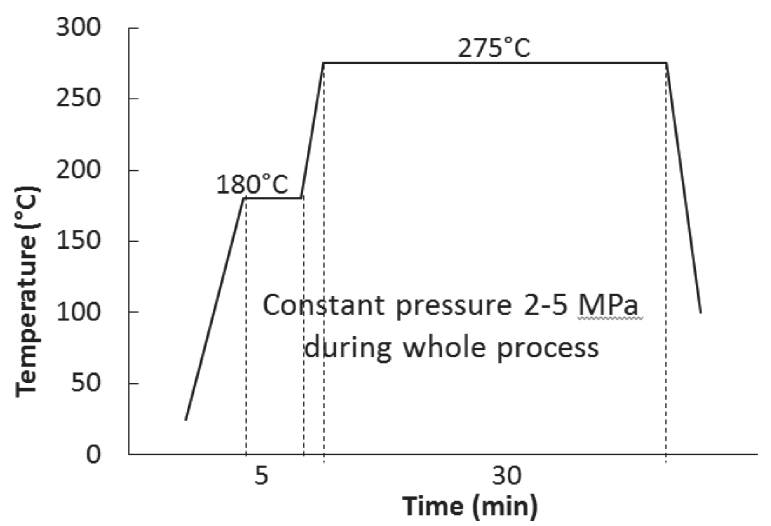

Fig. 1 Conventional drying and sintering profile for larege area attachment after the second paste print.

the silicon and the substrate. These two techniques combined could provide a non-destructive tool for evaluating the attachment formed by sintering nanosilver paste between the device and the substrate.

The steps involved in the previous process of sintering nanosilver paste for large area attachment are shown below and as follows: (a) the paste is printed on the substrate to a thickness of $50 \mu \mathrm{m}$; (b) the printed substrate is heated in air to $180^{\circ} \mathrm{C}$ at a ramp rate of $600^{\circ} \mathrm{C} /$ hour and with soak time of $300 \mathrm{~s}$; (d) a thin layer of paste (about 5 to $10 \mu \mathrm{m})$ paste is printed over the dried print and the chip is mounted on the wet print, and followed by heating using the profile shown in Fig.1. A pressure of 2-5 MPa applied on the chip is maintained throughout the sintering process. Although only $\sim 5 \mathrm{MPa}$ pressure is required for this procedure, the hot pressing step during the entire sintering stage presents some problems. The press is occupied during the entire process, thus limiting throughput. A conformal cushion to ensure uniform transmitted pressure must also withstand the elevated temperature, such as rubber or something similar. These will add to the complexity and cost of the manufacturing process. Reducing the processing temperature and keeping the pressing time during sintering short or eliminating it altogether should keep the cost down and make the process more feasible. An implied objective of this study is to determine under what conditions the process can be simplified, e.g., minimum temperature, time and pressure requirement. Since determining the bond strength of the die attachment for large-area devices is difficult, this study was aimed at evaluating the bonding quality under different processing conditions by nondestructive characterization techniques. While these methods may not be direct substitutes for mechanical tests, it is hoped that they will provide a reliable measure of an attachment's strength.

\section{Procedure}

\subsection{Sample fabrication}

The test samples consisted of direct bond copper (DBC) substrate and silicon chips bonded together with sintered nanosilver paste. The silver paste was provided by NBE technologies, LLC, Blacksburg, Virginia, and goes by the trade name of nanoTach. The thickness of the copper and alumina layers of DBC were $200 \mu \mathrm{m}$ and $380 \mu \mathrm{m}$, respectively. In lieu of actual devices, $200 \mu \mathrm{m}$ thick silicon chips were used. The DBC substrate had a coating of silver while the silicon was coated with a metallization consisting of $150 \mathrm{~nm} \mathrm{Cr}, 200 \mathrm{~nm} \mathrm{Ni}$ and $250 \mathrm{~nm} \mathrm{Ag}$ in succession by physical vapor deposition (PVD). The silver coatings were necessary for adhesion to the sintered silver. The DBC substrates and silicon wafers were cut into $14 \times 14 \mathrm{~mm}^{2}$ and $10 \times 10 \mathrm{~mm}^{2}$ pieces, respectively, for sample fabrication.

The silver paste attachment layer was deposited as a double print on the DBC substrate. An initial layer of nanosilver paste was printed with a wet print thickness of $50 \mu \mathrm{m}$ and dried at $180^{\circ} \mathrm{C}$ for $300 \mathrm{~s}$ after heating at a ramp rate of $300^{\circ} \mathrm{C} /$ hour. The second layer was printed on the dried paste with an estimated wet print thickness of $25 \mu \mathrm{m}$. The silicon chip was mounted on the printed paste, and the assembly was heated up following the profiles shown in Fig. 2. In order to evaluate the effects of pressure and tem-

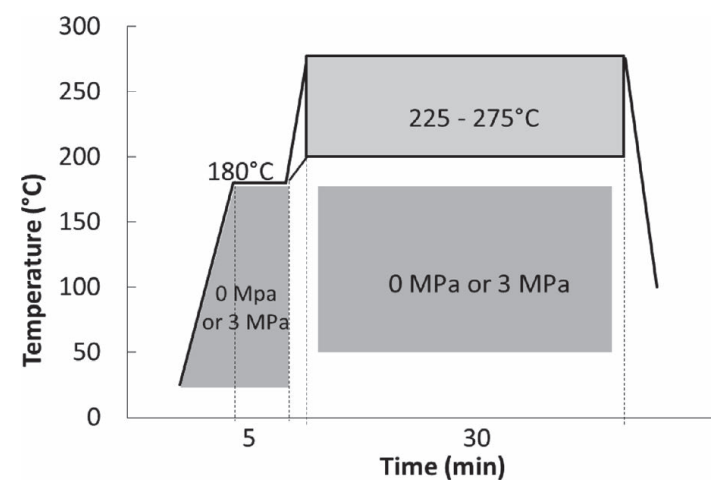

Fig. 2 Drying and sintering profiles used in the experiment.

Table 1 Different drying and sintering profiles.

\begin{tabular}{c|c|c|c}
\hline $\begin{array}{c}\text { Group } \\
\text { number }\end{array}$ & $\begin{array}{c}\text { Drying } \\
\text { pressure } \\
(\mathrm{MPa})\end{array}$ & $\begin{array}{c}\text { Sintering } \\
\text { temperature } \\
\left({ }^{\circ} \mathrm{C}\right)\end{array}$ & $\begin{array}{c}\text { Sintering } \\
\text { pressure } \\
(\mathrm{MPa})\end{array}$ \\
\hline $\mathrm{A}$ & 0 & 275 & 0 \\
\hline $\mathrm{B}$ & 0 & 275 & 3 \\
\hline $\mathrm{C}$ & 3 & 225 & 0 \\
\hline $\mathrm{D}$ & 3 & 225 & 3 \\
\hline $\mathrm{E}$ & 3 & 275 & 0 \\
\hline $\mathrm{F}$ & 3 & 275 & 3 \\
\hline
\end{tabular}




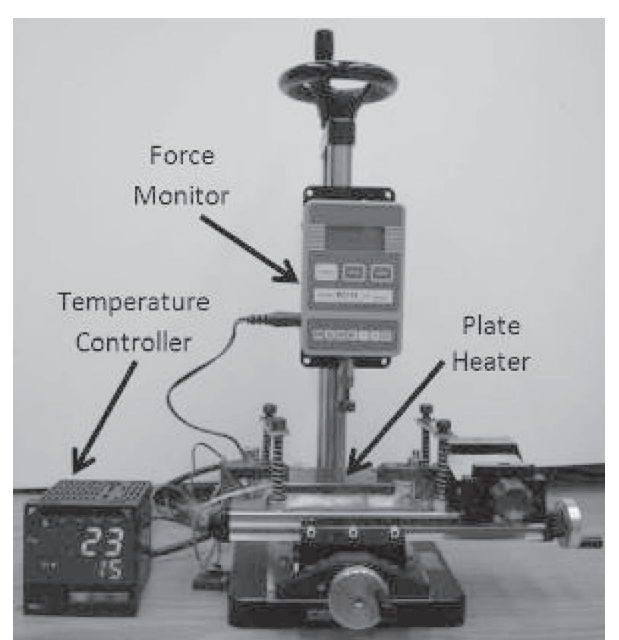

Fig. 3 Hot press for sample drying and sintering of the nanosilver paste in the silicon-DBC assembly.

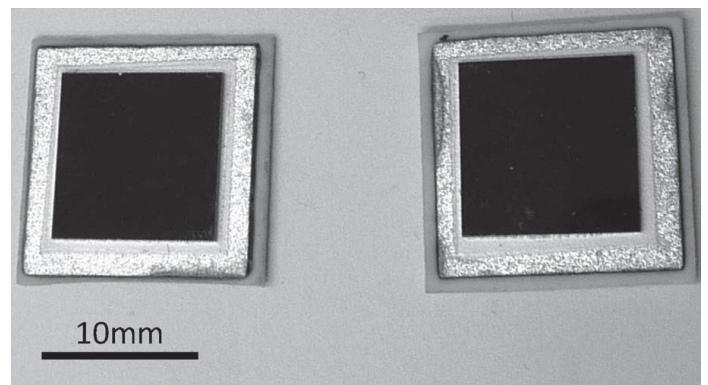

Fig. 4 Silicon chips attached to DBC substrates with sintered nanosilver paste.

perature during each stage, six different heating conditions were used and shown in Table 1 . Three replicates were fabricated for each heating condition. A press with a heated plate was used for pressure drying and sintering and is shown in Fig. 3. The sintered samples are shown in Fig. 4.

\subsection{Analytical equipment and methods}

\subsubsection{Micro X-ray computed tomography}

X-ray computed tomography is a non-destructive method for the imaging of internal structures such as the voids/cracks in the attachments that may form in a sintered silver attachment layer. In our study, a MicroXCT 400 from Xradia company was used for the X-ray CT scanning. When the images are obtained in the transmission mode, the lighter areas in the image indicate the presence of voids, cracks, or material of lower density. In the absorption mode, the opposite is true. It is also possible to obtain 3-dimensional virtual images of the attachment layer, thus enabling the determination of the exact locations and extent of defects within the silver layer.

In order to find out which step in the attachment process is responsible for crack formation, X-ray imaging was used to inspect samples, both after drying and after sintering. While, x-ray imaging allows the detection of the cracks and voids, it is unable to discriminate between a good bond and a poor bond. The image obtained from a completely detached chip may look similar to that of a strongly bonded chip. Therefore, it is necessary to pair X-ray imaging with another method that can provide an indication of the bond quality to make it useful in evaluating attachments made with nanosilver paste. A potentially useful parameter is the post-sintering curvature that develops on the bonded device. If the device has sufficient reflectivity, a simple laser scanning technique may be used to obtain the curvature. However, a poorly reflecting surface does not preclude the use of the sample curvature as a metric for bond quality since other methods should be available for measuring curvature. This paper covers only the laser scanning technique.

\subsubsection{Curvature measurement by laser scanning}

The rationale for using the device curvature as a metric for bond strength is as follows. Because of the existence of a mismatch between the coefficients of thermal expansion (CTE) of the silicon chip and DBC substrate, a sintered sample would develop a curvature after sintering. If the adjacent layers of the sample are perfectly bonded, the ideal curvature of the sample can be determined just by the material properties themselves.[10] In real cases, the measured curvature is always lower than the ideal curvature because the interfacial bonding is not perfect. However, the difference between the ideal and real curvatures can still reveal the quality of the bonding: the stronger the bond, the higher the measured curvature, assuming the attachment layer (sintered nanosilver) does not experience internal changes that dissipate the curvature. Obviously, this method will not be useful if the materials being bonded have very similar CTEs or if the surfaces being bonded are already deformed.

The principle behind the laser scanning technique for obtaining the curvature is shown in Fig. 5. The actual optical bench used for the measurements is shown in Fig. 6 . By moving the translation stage, the laser is able to scan a programmed length of the sample, and the deflected beam is detected by a position-sensitive detector some known distance away. The curvatures of all samples were measured after sintering. A more detailed description of the curvature measurement technique and apparatus can be found elsewhere.[11, 12] 


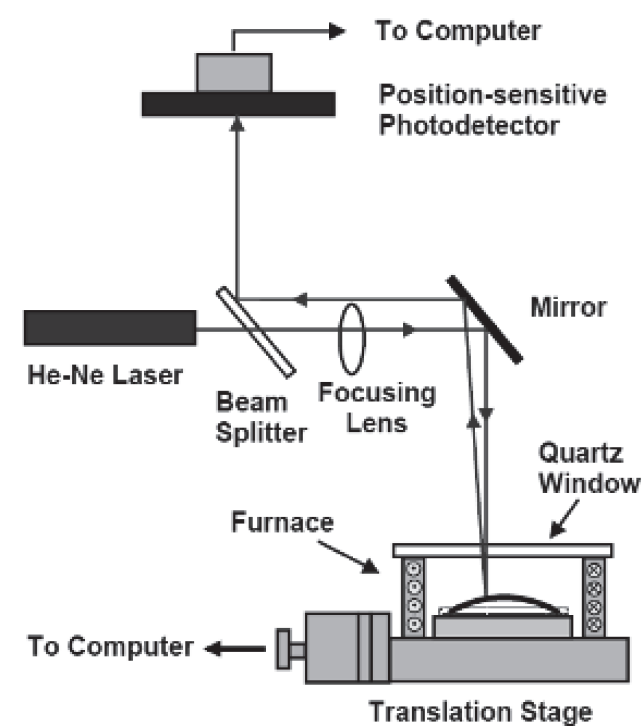

Fig. 5 Schematic of the curvature measurement technique involving laser scanning of the curved samples.

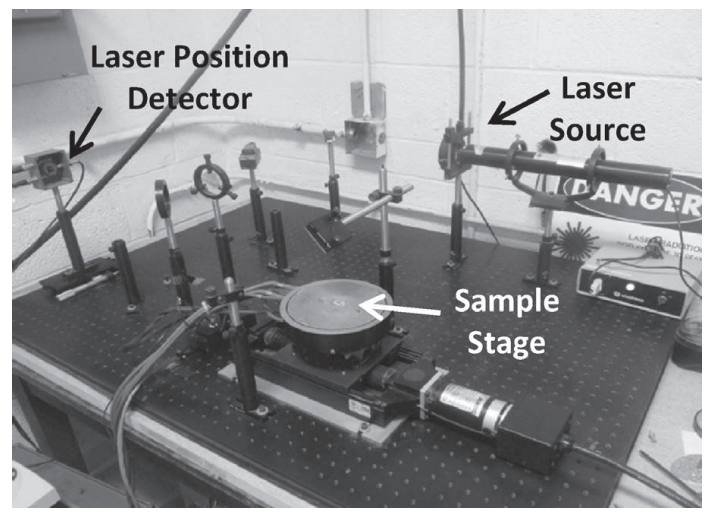

Fig. 6 Optical setup for determining the sintered sample curvature by laser scanning.

\section{Results and Discussion}

\subsection{X-ray images of sintered samples}

Figure 7 to Fig. 12 showed the transmission mode X-ray images for samples sintered under conditions in Table 1, respectively.

Figure 7 and Fig. 8 are for samples dried without pressure, and sintered at $275^{\circ} \mathrm{C}$. Figure 7 is for a sample sintered without pressure (Group A), and Fig. 8 is for a sample sintered with $3 \mathrm{MPa}$ pressure (Group B). Some wide cracks can be seen in Fig. 7, indicating poor bonding quality of samples heated (including drying and sintering) without any pressure. It is believed the cracks were formed because of the outgassing while solvents and binders in paste were evaporating and burning. Without any external pressure during the whole heating process, the outgassing problem can seriously affect the structure of the printed silver paste layers and cause poor bonding. Figure 8 shows the bonding quality of the samples dried

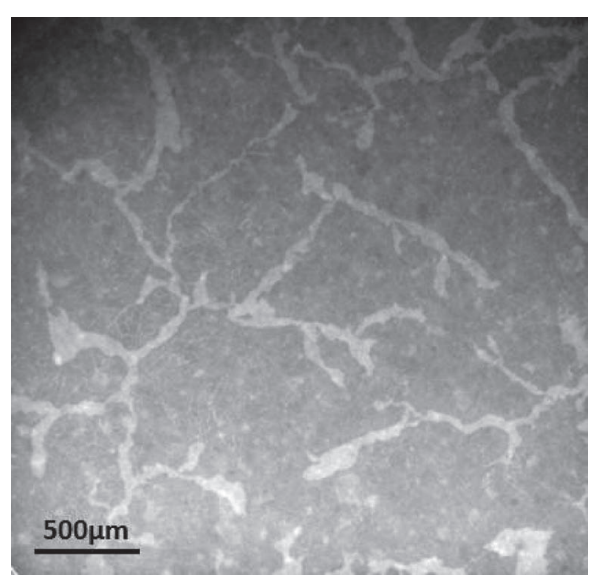

Fig. 7 X-ray transmission image of a sample dried without pressure and sintered at $275^{\circ} \mathrm{C}$ without pressure (Group A).

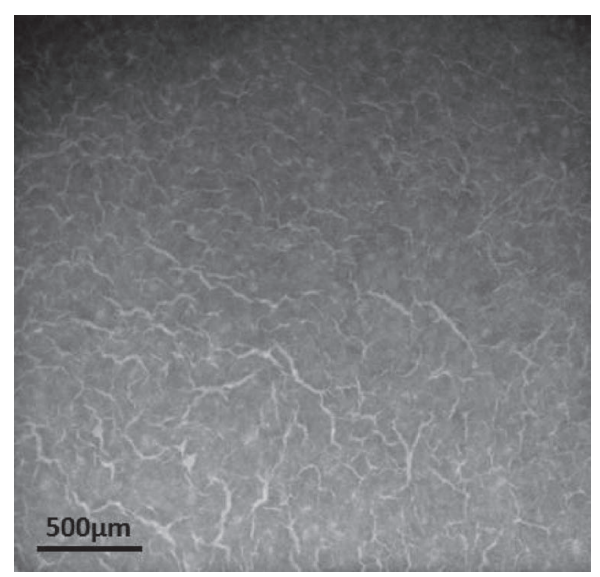

Fig. 8 X-ray transmission image of a sample dried without pressure and sintered at $275^{\circ} \mathrm{C}$ under $3 \mathrm{MPa}$ pressure (Group B).

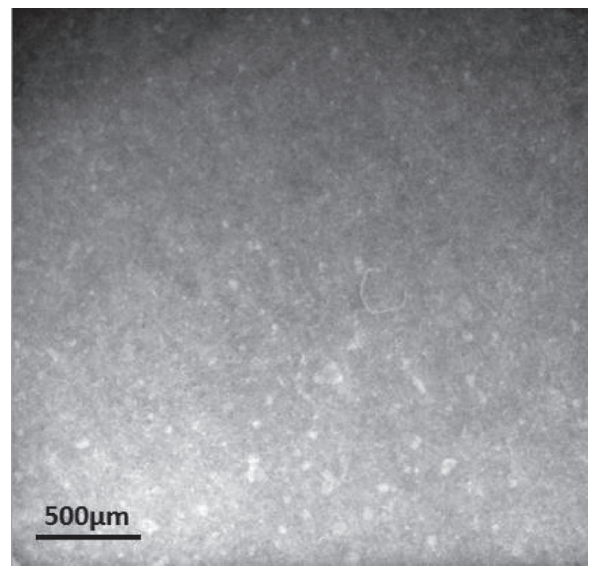

Fig. 9 X-ray transmission image of a sample dried under $3 \mathrm{MPa}$ pressure and sintered at $225^{\circ} \mathrm{C}$ without pressure (Group C).

without pressure and sintered at $275^{\circ} \mathrm{C}$ under $3 \mathrm{MPa}$ pressure. Unlike the bonding layer shown in Fig. 7, no wide cracks can be seen in Fig. 8, but a lot of tiny cracks can still be observed. This indicated that with applied external pressure, a better uniform bonding layer can be obtained, 


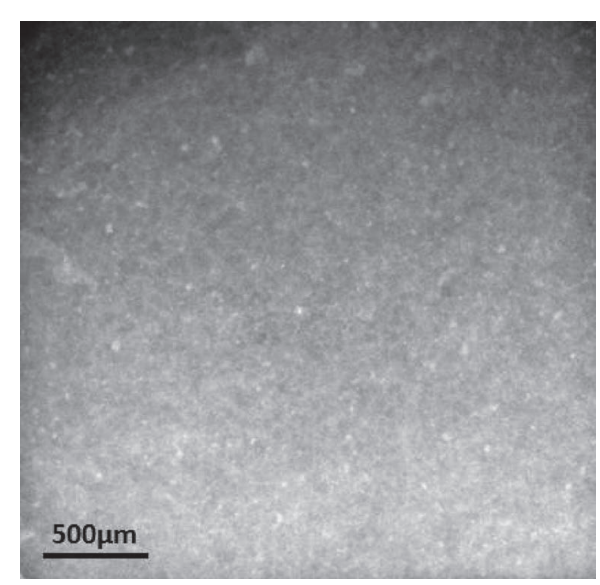

Fig. 10 X-ray transmission image of a sample dried under 3 $\mathrm{MPa}$ pressure and sintered at $225^{\circ} \mathrm{C}$ under $3 \mathrm{MPa}$ pressure (Group D).

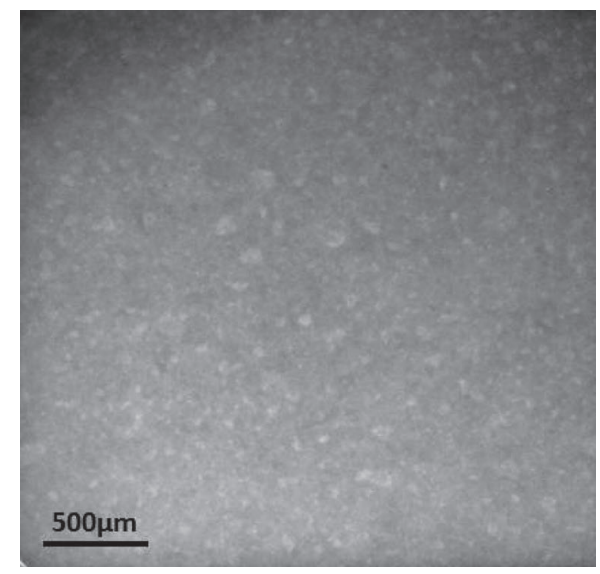

Fig. 11 X-ray transmission image of a sample dried under $3 \mathrm{MPa}$ pressure and sintered at $275^{\circ} \mathrm{C}$ without pressure (Group E).

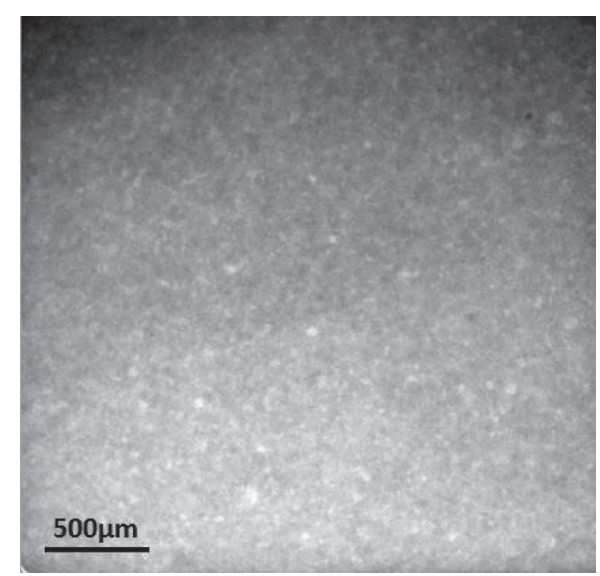

Fig. 12 X-ray transmission image of a sample dried under 3 $\mathrm{MPa}$ pressure and sintered at $275^{\circ} \mathrm{C}$ under $3 \mathrm{MPa}$ pressure (Group F).

and the bonding quality can be improved. In the former case, drying could have generated initial cracking that grew with further shrinkage during sintering. In the latter case, with pressure applied during sintering, an increase in shrinkage in the direction of the applied pressure (perpendicular to the substrate) reduced the amount of shrinkage in the in-plane direction necessary to accommodate the increased density, thus the absence of wide cracks.

Figure 9 to Fig. 12 are all for samples dried at $180^{\circ} \mathrm{C}$ under $3 \mathrm{MPa}$ pressure. Figure 9 (Group C) and Fig. 10 (Group D) are sintered at a low temperature $225^{\circ} \mathrm{C}$ (without and with pressure, respectively), while Fig. 11 (Group E) and Fig. 12 (Group F) are sintered at a high temperature $275^{\circ} \mathrm{C}$ (without and with pressure). All of the images showed that the sintered silver layer is remarkably uniform with no visible voids or cracks. The similarity of the images indicate that as long as an external pressure is applied during the drying stage, i.e., from room temperature to $180^{\circ} \mathrm{C}$, the bonding layer will be almost "solid", and cracks will hardly be generated after drying.

Comparing Group A (Fig. 7) with Group E (Fig. 11), or comparing Group B (Fig. 8) with Group F (Fig. 12), we clearly see the difference between two similar heating profiles, with only different pressure during the drying stage. This will lead to the same conclusion: as long as a sufficient pressure is applied during the drying stage, the pressure during the sintering stage will not affect the uniformity of the bonding layers.

Comparing Group C and D (Fig. 9 and 10) with Group E and F (Fig. 11 and 12), no big difference can be observed. This implies the bond uniformity is not sensitive to the sintering temperature, at least visually. As stated earlier, uniformity of the sintered layer microstructure does not necessarily mean high bond strength.

Some white dots can also be seen in Fig. 7 to Fig. 12 . Those white dots in the X-ray transmission images are from the DBC substrate. There were voids between copper and alumina layers. Figure 13 showed the reconstructed sliced layer of the copper-alumina interface, where black color represents voids while bright color represents solids. X-ray transmission rate is very sensitive to the voids, and the brighter dots in the transmission images represent higher transmission of X-ray through the voids.

Figure 14 is a reconstructed X-ray image showing only the sintered silver layer to prove the uniformity of the bonding layer. The image was from a sample in Group $\mathrm{E}$ (dried under $3 \mathrm{MPa}$, sintered at $275^{\circ} \mathrm{C}$ without pressure). The silver layer is generally uniform with only a few tiny cracks and pinholes possibly present. This type of structure is typical of nanosilver paste when properly deposited, dried and sintered. Solder, on the other hand, may have voids that are easily detected by X-ray imaging or some 


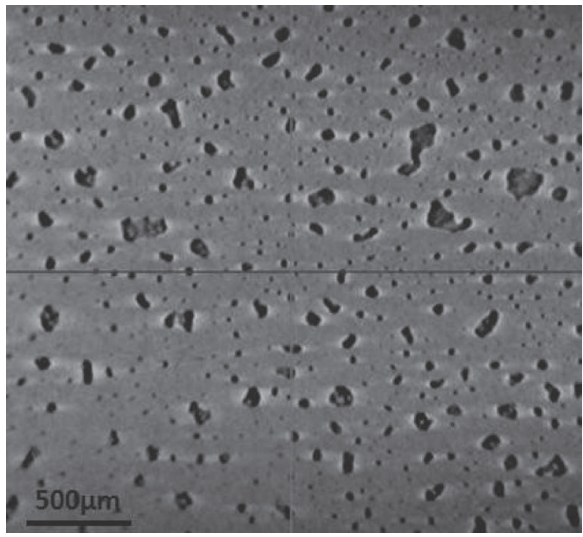

Fig. 13 X-ray reconstructed image of the interface between copper and alumina in DBC substrate.

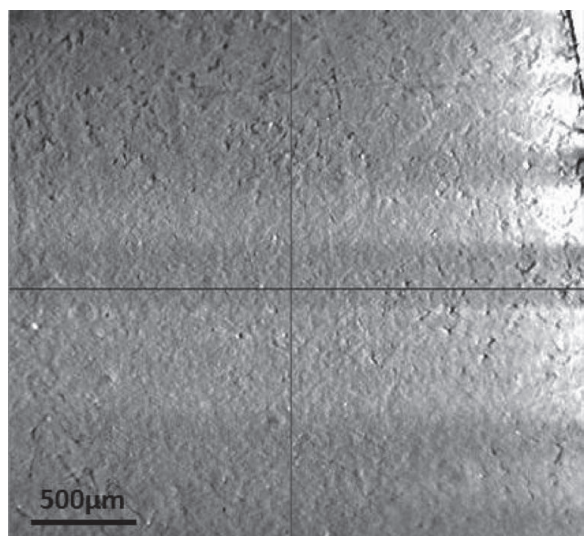

Fig. 14 X-ray reconstructed image of the sintered nanosilver paste layer in the sample from Group E.

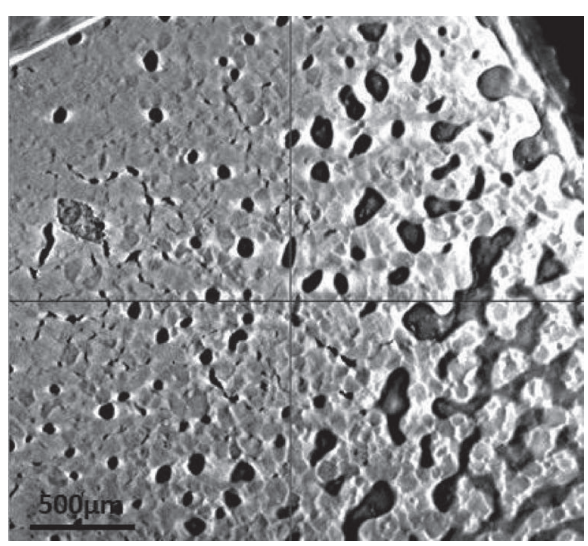

Fig. 15 X-ray reconstructed image of sintered micron-sized silver layer in a commercial module.

other means. These voids also tend have a circular shape, a result of the melting and solidification process. Finally, for purposes of comparison, the sintered silver layer attachment in a commercial module is shown in Fig. 15. The initial silver particles from the sintering material are seen at the micrometer scale. Voids and cracks are present in significant numbers. In contrast, the attachment layer
Table 2 Geometry and Material Properties of DBC, Sintered Nano-Silver Layer, and Silicon.

\begin{tabular}{c|c|c}
\hline \multirow{3}{*}{$\mathrm{CBC}$} & $\mathrm{Cu}$ & $\begin{array}{c}\text { Thickness: } 200 \mu \mathrm{m} \\
\text { CTE: } 16.5 \times 10^{-6} \mathrm{~K}^{-1} \\
\text { Young's Modulus: } 120 \mathrm{GPa}\end{array}$ \\
\cline { 2 - 3 } & \multirow{2}{*}{$\mathrm{Al}_{2} \mathrm{O}_{3}$} & $\begin{array}{c}\text { Thickness: } 380 \mu \mathrm{m} \\
\text { CTE: } 8.1 \times 10^{-6} \mathrm{~K}^{-1} \\
\text { Sintered silver layer }\end{array}$ \\
& Young's Modulus: $300 \mathrm{GPa}$ \\
\hline \multirow{2}{*}{ Silicon } & Thickness: $15 \mu \mathrm{m}$ \\
& CTE: $18.9 \times 10^{-6} \mathrm{~K}^{-1}$ \\
& Young's Modulus: $10 \mathrm{GPa}$ \\
\hline & Thickness: $200 \mu \mathrm{m}$ \\
& CTE: $2.6 \times 10^{-6} \mathrm{~K}^{-1}$ \\
& Young's Modulus: $185 \mathrm{GPa}$ \\
\hline
\end{tabular}

from sintered nanosilver paste shown in Fig. 14 has better uniformity and very few defects at the same scale.

\subsection{Curvatures of sintered samples}

The geometry and material properties of the fabricated samples with the sintered nanoscale silver attachment are shown in Table 2 . The theoretical curvature of the samples based on Hsueh[10] should be $2.26 \mathrm{~m}^{-1}$ for the samples sintered at $275^{\circ} \mathrm{C}$ and $1.81 \mathrm{~m}^{-1}$ for the samples sintered at $225^{\circ} \mathrm{C}$. The actual curvatures obtained by laser scanning are shown in Table 3. The measured curvatures are lower than the theoretical values. It is likely that the actual samples did not achieve the infinite bonding between the material layers such that the resulting curvature is lower than the ideal or theoretical value. Nevertheless, it should not detract from the utility of the curvature measurement technique as a nondestructive method for evaluating the bond quality achieved with the sintered nanosilver paste. It should be just a matter of properly calibrating the technique against some baseline measurements. As for the actual shear strength of the samples, none of the samples could be die-sheared without cracking the silicon chips, an indication that the silver bond has achieved high strength. The trend that a higher curvature represents a higher bonding strength appears to hold. A more precise correlation between curvature and bonding strength will be the subject of future research.

From Table 3, the curvature of Group A is the lowest, which very close to zero. It means that the bonding quality of the samples dried without pressure and sintered at $275^{\circ} \mathrm{C}$ without pressure is the worst among all the heating conditions. This is in good agreement with the results from X-ray imaging.

The curvatures of Group C were $0.59 \pm 0.06 \mathrm{~m}^{-1}$, showing the samples sintered at $225^{\circ} \mathrm{C}$ without pressure devel- 
Table 3 Curvatures Measured by Laser Scanner.

\begin{tabular}{c|c|c|c|c}
\hline $\begin{array}{c}\text { Group } \\
\text { number }\end{array}$ & $\begin{array}{c}\text { Drying } \\
\text { pressure } \\
(\mathrm{MPa})\end{array}$ & $\begin{array}{c}\text { Sintering } \\
\text { temperature } \\
\left({ }^{\circ} \mathrm{C}\right)\end{array}$ & $\begin{array}{c}\text { Sintering } \\
\text { pressure } \\
(\mathrm{MPa})\end{array}$ & $\begin{array}{c}\text { Curvature } \\
\left(\mathrm{m}^{-1}\right)\end{array}$ \\
\hline $\mathrm{A}$ & 0 & 275 & 0 & $0.09 \pm 0.01$ \\
\hline $\mathrm{B}$ & 0 & 275 & 3 & $0.80 \pm 0.13$ \\
\hline $\mathrm{C}$ & 3 & 225 & 0 & $0.59 \pm 0.06$ \\
\hline $\mathrm{D}$ & 3 & 225 & 3 & $0.73 \pm 0.13$ \\
\hline $\mathrm{E}$ & 3 & 275 & 0 & $0.84 \pm 0.10$ \\
\hline $\mathrm{F}$ & 3 & 275 & 3 & $0.97 \pm 0.09$ \\
\hline
\end{tabular}

oped lower curvature than those of Group D which were sintered at $225^{\circ} \mathrm{C}$ with $3 \mathrm{MPa}$ pressure $\left(0.73 \pm 0.13 \mathrm{~m}^{-1}\right)$, a change of nearly a quarter. Similarly, the curvatures of Group E (samples sintered at $275^{\circ} \mathrm{C}$ without pressure) are lower than those of Group F (samples sintered at $275^{\circ} \mathrm{C}$ with $3 \mathrm{MPa}$ pressure), a smaller increment percentagewise but of similar amount compared with the $225^{\circ} \mathrm{C}$ condition. Comparing with the results of samples sintered at $225^{\circ} \mathrm{C}$ and $275^{\circ} \mathrm{C}$, we found that the curvatures of pressure sintered samples were consistently higher than the curvatures of corresponding non-pressure sintered samples. This implies that the applied pressure during sintering may have an effect on the final bonding, though not very significant, when looking at curvature alone, in the temperature range from $225^{\circ} \mathrm{C}$ to $275^{\circ} \mathrm{C}$.

Moreover, when comparing the curvatures of Group C with Group E, (or Group D with Group F), we found the curvatures of the samples sintered at $275^{\circ} \mathrm{C}$ was approximately $0.15 \mathrm{~m}^{-1}$ larger than the samples sintered at $225^{\circ} \mathrm{C}$, which implied that bonding qualities of the silver layers sintered at a $275^{\circ} \mathrm{C}$ were better than those sintered at $225^{\circ} \mathrm{C}$. This cannot be explained by the uniformity of silver bonding layers revealed from X-ray images. One possible reason is that $225^{\circ} \mathrm{C}$ may be too low for the binder to burn off quickly thus impeding the sintering process and the development of the ensuing microstructure. The development of the interfacial bond may also be affected although the x-ray images will not show such effects. However, the result implies lower bond strength.

Another important observation was that the curvature of Group B (zero pressure drying) was almost as high as Group E and F, indicating that so long as pressure is applied during sintering, the drying pressure used is practically inconsequential to the final result. A question now arises on what heating profile is preferred. Since it is desirable from a processing standpoint to limit the equipment and materials requirements and keep the process simple, the results may point to some process parameters that will be satisfactory. If we disregard the sintered microstructure and focus on the curvature, assuming that bond strength scales with it, two conditions stand out as alternatives. For the condition used in Group D, applying a $3 \mathrm{MPa}$ pressure throughout while using a peak temperature of $225^{\circ} \mathrm{C}$ gives a sufficiently high curvature. Alternatively, by increasing the peak temperature to $275^{\circ} \mathrm{C}$, the pressure may be skipped during the sintering stage while still producing a high curvature (Group E). If fixturing is going to be an issue, i.e., the need for a high-temperature cushion to deliver uniform pressure on the chip(s), then the latter is desirable. If however, the parts are sensitive to temperature, then a lower sintering temperature may be desirable, thus defaulting to Group D conditions. It should be noted however that temperature is a more powerful parameter than pressure in the densification kinetics during solidstate sintering, as is the case with nanoscale silver paste.

\subsection{Cross-sectional analysis of sintered samples}

In order to confirm that the observation from the nondestructive characterization is correct, some samples were cut to observe their cross-sections. Figure 16 to Fig. 18 showed the cross-sections of samples in Group A (dried without pressure, sintered at $275^{\circ} \mathrm{C}$ without pressure), Group D (dried under $3 \mathrm{MPa}$, sintered at $225^{\circ} \mathrm{C}$ under 3 $\mathrm{MPa}$ ) and Group E (dried under $3 \mathrm{MPa}$, sintered at $275^{\circ} \mathrm{C}$ without pressure), respectively.

In Fig. 16, voids can be seen in the cross-section of sintered silver layer, confirming the wide river-like cracks in the X-ray image in Fig. 7. A tiny crack between silver and silicon was also observed, indicating the delamination between silicon device and bonding layer, which led to low curvatures $\left(0.09 \pm 0.01 \mathrm{~m}^{-1}\right)$ of samples in Group A. Figure 17 and Fig. 18 showed the sintered silver layers were completely attached to both copper and silicon. No obvious 


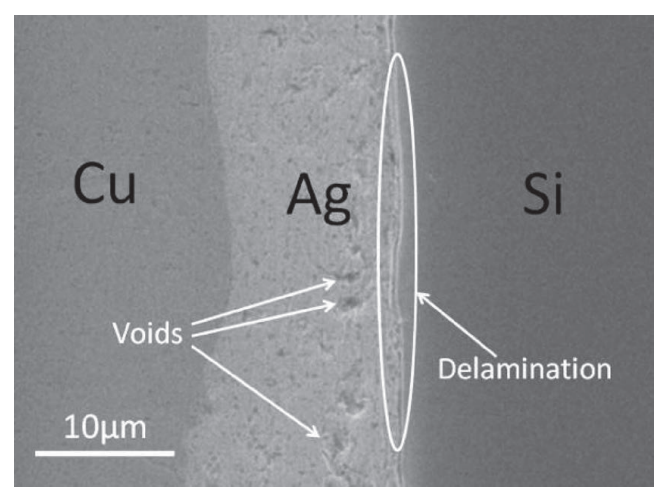

Fig. 16 SEM cross-section image of a sample dried without pressure and sintered at $275^{\circ} \mathrm{C}$ without pressure (Group A).

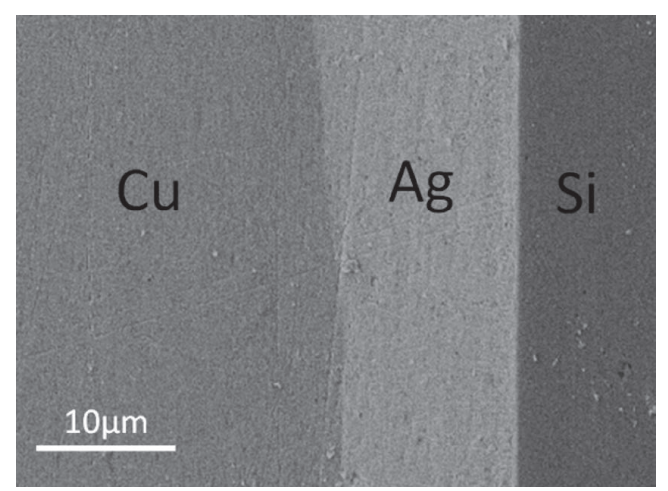

Fig. 17 SEM cross-section image of a sample dried under 3 $\mathrm{MPa}$ pressure and sintered at $225^{\circ} \mathrm{C}$ under $3 \mathrm{MPa}$ pressure (Group D).

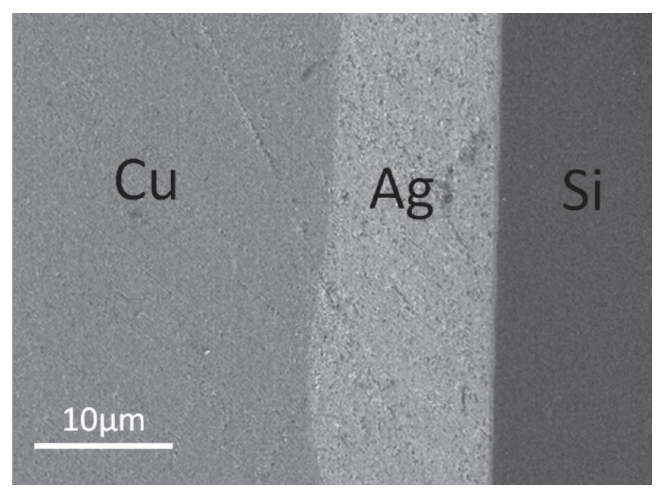

Fig. 18 SEM cross-section image of a sample dried under $3 \mathrm{MPa}$ pressure and sintered at $275^{\circ} \mathrm{C}$ without pressure (Group E).

voids and cracks can be found within the scale. They are in good agreement with the X-ray images in Fig. 10 and Fig. 11.

\section{Conclusion}

Large-area $\left(>1 \mathrm{~cm}^{2}\right)$ silicon chips were attached to directbond copper substrates by sintering a nanosilver paste at temperatures below $300^{\circ} \mathrm{C}$ and pressures up to $3 \mathrm{MPa}$. The bonded structures were characterized nondestruc- tively by X-ray computed tomography (CT) and curvature measurements using a laser-scanning system. X-ray images of the sintered nanoscale silver showed that so long as a sufficient pressure is applied during the drying stage, the pressure, or absence thereof, during the sintering stage will not affect the uniformity of the bonding layer and a uniform microstructure will be obtained with very few observable defects. The presence of measurable curvature on the attached silicon devices indicated the formation of a strong bond after sintering. The curvature data showed that applying pressure during drying resulted in curvatures that are comparable with those observed when sintering under pressure, particularly at the higher temperature. As expected, sintering at $275^{\circ} \mathrm{C}$ would produce higher curvature than at $225^{\circ} \mathrm{C}$. In general, applying pressure during drying and/or sintering and increasing the sintering temperature improved the microstructure while also increasing the observed curvature. An important observation is that it is possible to skip the applied pressure during sintering if pressure is applied during drying and keeping the sintering temperature sufficiently high, e.g. at $275^{\circ} \mathrm{C}$, and still obtain favorable microstructure and curvature. This could go a long way in simplifying the device attachment process and reduce both the technical and cost barriers to adopting sintered nanoscale silver paste as a joint material.

\section{Acknowledgement}

The CT imaging of the samples was performed in the SBES Advanced Multiscale Computed Tomography Facility (SAM-CT) at Virginia Tech, which is supported by an NIH SIG grant (RR025667), an NSF MRI grant (CMMI0923297), as well as ICTAS and SBES internal funding. The authors are also grateful for financial support provided by the United States Army Research Laboratory under Contract No. W911NF-07-R-0001.

\section{References}

[1] G. Q. Lu, J. N. Calata, Z. Y. Zhang, and J. G. Bai, "Lead-free, low-temperature sintering die-attach technique for high-performance and high-temperature packaging," Proceedings of the Sixth IEEE CPMT Conference on High Density Microsystem Design and Packaging and Component Failure Analysis (HDP'04), pp. 42-46, 2004.

[2] J. G. F. Bai and G. Q. Lu, "Thermomechanical reliability of low-temperature sintered silver die attached $\mathrm{SiC}$ power device assembly," IEEE Transactions on 
Device and Materials Reliability, Vol. 6, pp. 436-441, 2006.

[3] K. W. Xiao, T. G. Lei, et al., "Creep behavior of sintered nano-silver paste," Proceedings of Center for Power Electronics Systems Annual Seminar, April 11-13, 2010.

[4] J. N. Calata, T. G. Lei, and G. Q. Lu, "Sintered nanosilver paste for high-temperature power semiconductor device attachment," International Journal of Materials \& Product Technology, Vol. 34, pp. 95-110, 2009.

[5] T. G. Lei, J. N. Calata, et al., "Low-Temperature Sintering of Nanoscale Silver Paste for Attaching LargeArea $\left(>100 \mathrm{~mm}^{2}\right.$ ) Chips," IEEE Transactions on Components and Packaging Technologies, Vol. 33, pp. 98-104, 2010.

[6] C. Gobl and J. Faltenbacher, "Low temperature sinter technology die attachment for power electronic application,” CIPS2010, March 16-18, 2010.

[7] Z. Zhang and G. Q. Lu, "Pressure-assisted low-temperature sintering of silver paste as an alternative die-attach solution to solder reflow," IEEE Transactions on Electronics Packaging Manufacturing, Vol. 25, pp. 279-283, 2002.

[8] J. G. Bai, Z. Z. Zhang, J. N. Calata, and G. Q. Lu,
"Low-temperature sintered nanoscale silver as a novel semiconductor device-metallized substrate interconnect material," IEEE Transactions on Components and Packaging Technologies, Vol. 29, pp. 589-593, 2006.

[9] T. Wang, X. Chen, G. Q. Lu, and G. Y. Lei, "Low-temperature sintering with nano-silver paste in dieattached interconnection," Journal of Electronic Materials, Vol. 36, pp. 1333-1340, 2007.

[10] C. H. Hsueh, "Modeling of elastic deformation of multilayers due to residual stresses and external bending," Journal of Applied Physics, Vol. 91, pp. 9652-9656, 2002.

[11] J. N. Calata, "Densification Behavior of Ceramic and Crystallizable Glass Materials Constrained on a Rigid Substrate," Materials Science and Engineering, Virginia Polytechnic Institute and State University, Blacksburg, 2005.

[12] Z.B. Zhao, J. Hershberger, S. M. Yalisove, and J. C. Bilello, "Determination of residual stress in thin films: a comparative study of X-ray topography versus laser curvature method," Thin Solid Films, Vol. 415, pp. 21-31, 2002. 